\title{
Execution of Computerized Management Systems in Facility Maintenance Services of Government Hospitals
}

\author{
Md Azree Othuman Mydin ${ }^{1, a}$, Noor Farisya Azahar ${ }^{2}$, Norazmawati Md Sani ${ }^{3}$, Noor Faisal Abas ${ }^{4}$ \\ ${ }^{1,2,3,4}$ School of Housing, Building and Planning, Universiti Sains Malaysia, 11800, Penang, Malaysia
}

\begin{abstract}
Maintenance management of a hospital is the most important element in determining the ability of a hospital to provide its services successfully. On 28th October 1996, the Ministry of Health (MOH) privatized five Hospital Support Services (HSS), one of them being Facility and Engineering Maintenance Services (FEMS). Currently, the Ministry has granted concessions for the privatized services to three contractors where they have established and are maintaining their own basic Management Information System (MIS) to manage the entire project and track the work performed for all of their services. These MISs consist of a variety of modules which help maintenance strategies adopted in a building run smoothly. The purpose of this paper is to study the utilization of computerized management system modules in the MISs of those three HSS providers and to investigate problems that have occurred during the utilization of these systems. This study was conducted in the form of case studies at three different hospitals that subscribed to three different concession companies. Targeting maintenance staff and users of computerized management systems, 60 sets of questionnaires were distributed and interview sessions were conducted. This study will also highlight the challenges of using computerized management systems and propose suitable recommendations to improve the utilization of such systems.
\end{abstract}

\section{Introduction}

A hospital refers to any building or part thereof that is designed, adapted or used for the care, accommodation or treatment of the sick, infirm, aged, convalescent or pregnant [1]. Hospitals are part of a government sector in Malaysia that have many assets but also require maintenance to prevent these assets from deterioration.

Currently, the Ministry has granted concessions for the privatized services of FEMS to three contractors, namely, Faber Medi-serve Sdn. Bhd., Radicare (M) Sdn. Bhd. and Medivest Sdn. Bhd. FEMS is concerned with efficient and regular servicing of plants and equipment, minimizing breakdowns and interruptions, prompt response and rectification when things do go wrong, maximizing system efficiency and energy conservation, as well as future planning. Prior to the implementation of the privatization program in Malaysia, all hospital buildings performed maintenance work on buildings using a direct labour system (in-house). All three parties to whom the services have now been contracted are to provide standardized Computerized Management

${ }^{\text {a }}$ Corresponding author : azree@usm.my 
Information Systems, giving online information to the Ministry of Health office in Putrajaya, the State Health Director's offices, and the Hospital Directors' office.

To ensure that maintenance works smoothly, a maintenance management system that performs systematically and effectively is required. All data and information must be recorded to carry out maintenance work and should be coordinated in a system that is efficient and accessible. For this reason, computers are now recognized as powerful tools for maintenance as only a computer has the ability to store, retrieve, calculate, organize, and present vast amounts of data efficiently and accurately [2]. Computerized management systems are very versatile because most systems are developed in a modular design for various maintenance functions and they can be customized to specific applications. The basic modules in computerized management systems include equipment, inventory, purchasing, personnel, preventive maintenance, predictive maintenance, work order, contractors and rebuilds [3]. They can also provide historical, current, and future information in both summary and detailed format [2]. All these modules are related to each other and Figure 1 shows the basic relationship between them. However, these modules are controlled by different kinds of access levels for maintenance staff because of differences in the scope of work.

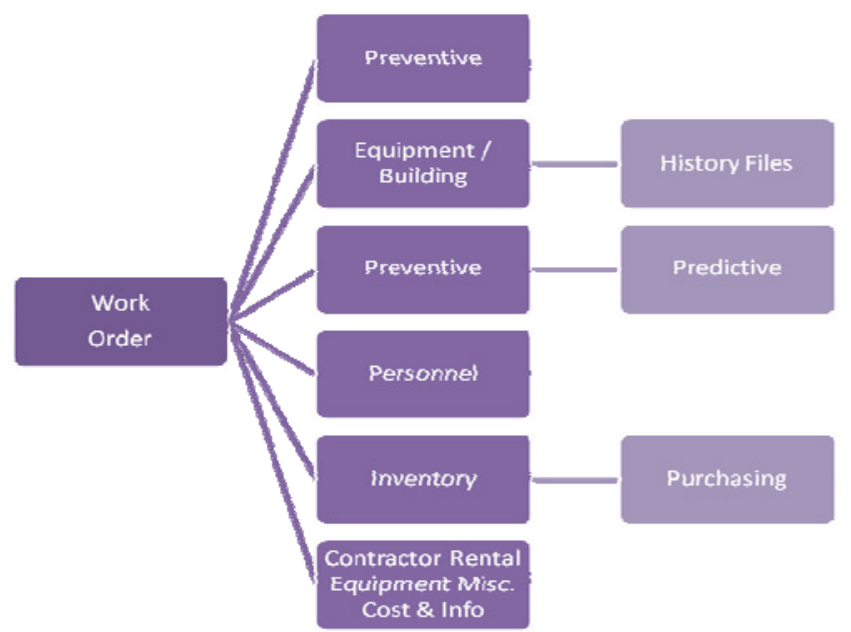

Fig. 1. Relationship between computerized management modules.

\section{Methodology}

Several strategies were approached to gather sufficient and reliable data. The first approach involved fieldwork, where questionnaire surveys were distributed. The respondents were chosen based on their involvement in computerized management or they were workers who faced difficulty using features of their computerized systems. Those questioned came from different positions including facilities managers, engineers, supervisors, technical officers, technicians, store keepers, FEMS administration staff and data entry staff. Interview sessions with several maintenance staff members were conducted in order to get clearer explanations and supporting information to add to the questionnaires. Secondary data were then obtained from a review of literature including journals, books, articles and research papers.

Three hospitals were selected for this study. These hospitals were located in different zones, namely Zone A, Zone B and Zone C in Malaysia. They were purposely chosen because they were maintained by different concession companies that had their own unique computerized management systems. The three hospitals were Hospital Tampin in Negeri Sembilan, Hospital Serdang in Selangor, and Hospital Kepala Batas, in Pulau Pinang.

Each site was given 20 sets of questionnaires, making the total number of questionnaires distributed 60. However, only 43 questionnaires were returned. 


\section{Findings and Discussion}

\subsection{Computerized Management Modules}

According to Table 1, data analysis for the computerized management modules available in each system of the different concession companies showed that Work Order Management ranked highest, with $67 \%$ of respondents stating that they were familiar with this module. Meanwhile, other features were not as well known, especially Budget/Cost Function.

Table 1: Modules available in different computerized systems

\begin{tabular}{|l|c|c|}
\hline \multicolumn{1}{|c|}{ Modules Application } & Response Frequency & $\begin{array}{c}\text { Percentage } \\
\mathbf{\%}\end{array}$ \\
\hline Work Order Management & 29 & 67 \\
\hline Planning Function & 7 & 16 \\
\hline Scheduling Function & 15 & 34 \\
\hline Budget/ Cost Function & 5 & 12 \\
\hline Spare Part Management & 10 & 23 \\
\hline Technical Reporting & 13 & 30 \\
\hline
\end{tabular}

It was found that all of the computerized maintenance system modules for every concession company involved in this study were the same. These three concession companies utilized the modules shown in Table 1 more frequently than the other features required by the MOH. The only difference that could be found was the interface of each system. The level of security to access certain features of the computerized management modules was different for different designations in the company. As shown in Table 1, it can be concluded that the module most frequently utilized in each computerized system was Work Order Management. This statement is supported by Figure 2 below, which indicates that most of the respondents who participated in this study were technicians. Technicians are the most frequent users of computerized systems as they are the people responsible for carrying out most of the maintenance work in a building.

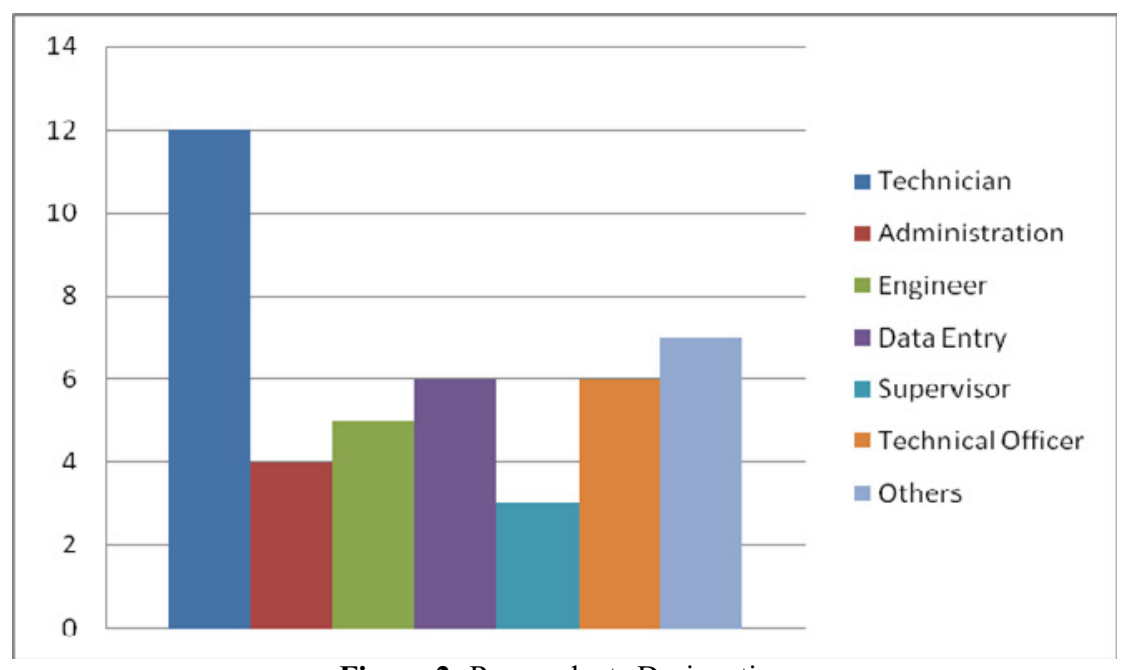

Figure 2: Respondents Designation

\subsection{Computerized System Training upon Commencing Working}


From analysis of the data, 33 respondents who accounted for $77 \%$ of those who completed the questionnaire said they had never received formal training on how to fully utilize the in-house computerized management system. Training has been identified as one of the largest weaknesses in the present maintenance structure in the US [3]. However, from interview sessions conducted with respondents holding higher level positions in their respective company, i.e. facilities managers, engineers and supervisors, they claimed to be well trained to fully utilize the systems. This was because these personnel held authority and were involved in critical processes like making decisions, planning as well as executing maintenance programs and strategies. However, they believed that all maintenance staff should be trained to use computerized systems so that they can understand the overall maintenance workflow and gain a better understanding of their scope of work.

\subsection{Analysis of Difficulty in Using Computerized Management Systems}

Table 2 shows a list of challenges that may occur while using a computerized management system and the level of difficulty of each challenge. This analysis was calculated using Likert Scaling. The highest score represents the main difficulty followed by other options according to the mean level of the highest score to the lowest mean score [4]. The respondents agreed that work order assignment was the most difficult challenge when using computerized management systems. The researchers were able to better understand this by analysing the comment column in each questionnaire. One of the respondents from Zone B stated that they found the usage of paper for delivering the work order assignment to be a burden. It would apparently become harder when an irresponsible technician incharge of a work order would pass his or her task onto another technician, thereby leading to the loss of the work order. Furthermore, although work order priority was often practiced in every concession company, incompetent persons in-charge appeared to always take their tasks for granted, finally resulting in a fee deduction.

Table 2: Level of difficulty of computerized management challenges

\begin{tabular}{|c|c|c|c|c|}
\hline Challenges & Often & Occasionally & Rarely & Never \\
\hline Work order assignment & $37 \%$ & $7 \%$ & $49 \%$ & $7 \%$ \\
\hline Environmental regulation compliance & $30 \%$ & $14 \%$ & $49 \%$ & $7 \%$ \\
\hline Safety regulation compliance & $23 \%$ & $21 \%$ & $49 \%$ & $7 \%$ \\
\hline Workforce management & $23 \%$ & $12 \%$ & $40 \%$ & $26 \%$ \\
\hline Forecasting labour requirement & $19 \%$ & $16 \%$ & $47 \%$ & $19 \%$ \\
\hline Access to historical reports & $16 \%$ & $21 \%$ & $37 \%$ & $26 \%$ \\
\hline Maintaining accurate inventory levels & $14 \%$ & $14 \%$ & $63 \%$ & $9 \%$ \\
\hline Managing purchase orders & $12 \%$ & $7 \%$ & $67 \%$ & $14 \%$ \\
\hline Tracking asset depreciation & $9 \%$ & $14 \%$ & $53 \%$ & $23 \%$ \\
\hline Reducing maintenance costs & $9 \%$ & $37 \%$ & $37 \%$ & $16 \%$ \\
\hline Asset failure downtime & $9 \%$ & $16 \%$ & $56 \%$ & $19 \%$ \\
\hline Reducing repair costs & $7 \%$ & $37 \%$ & $49 \%$ & $7 \%$ \\
\hline Controlling administrative costs & $7 \%$ & $9 \%$ & $56 \%$ & $28 \%$ \\
\hline Recurring maintenance scheduling & $5 \%$ & $28 \%$ & $40 \%$ & $28 \%$ \\
\hline
\end{tabular}

\section{Recommendations}

As mentioned in section 3.2, training is the most crutial phase before intergrating or upgrading a new system. From interview sessions that were conducted during the site visits, two respondents from two different sites suggested that their companies' headquaters conduct training about computerized systems used by the companies. Such training would quickly provide maintenance staff and operators with useful instructions so that they could follow guidelines and performance indicators set by the Ministry. This would also contribute to a healthy working environment, where everybody would 
always be informed and up-to-date about services they provide to their clients. Furthermore, it would help avoid issues and conflicts between contractors, clients and also the Ministry.

A hospital is a building that must always maintain a high-performance when it comes to serving the public, wether in expected or unexpected moments. Therefore, hospitals need to always be fully maintained and up to standard. Hospital buildings contain emense amounts of equipment and the larger the hospital, the more that needs to be maintained. Since all three of the contractors in this study elected to take on all aspects of maintenance in their respective hospitals, they must rely on an elaborate and fast computerized management system to support maintenance activities. Furtermore, the server speed has to be increased to efficiently deliver or receive information as well as to avoid complaints from users. A full-speed server is also important while updating work orders and keying in data in order to increase maintenace efficiency and effectiveness.

\section{Conclusion}

From the survey, it can be concluded that the modules of computerized management systems in the studied sites were not fully utilized by their users. With computerized maintenance management systems as the backbone of work processes, it is important to understand the value that these systems add, as well as areas for future growth and improvement. It was also found that maintenance staff did not have enough knowledge about their own system. This became evident when extracting data from questionnaires, where the question was not fully answered or respondents neglected to answer the questionnaire. The challenges of operating a computerized sytem could have been lessened if more effort was put into conducting training sessions to increase workers' knowledge about their own system. There are certain positive outcomes and areas for potential improvement that emerge from this survey. It is hoped that the results presented herein can raise awareness so that additional benefits can be obtained for computerized management systems in the future. This can be done by focusing on existing strengths and implementing effective initiatives to address the weaknesses.

\section{Acknowledgement}

The authors would like to thank the funding bodies of this research: Universiti Sains Malaysia under USM Short Term Grant. No. 304/PPBGN/6312147

\section{References}

1. Laws of Malaysia (1995), Fifth Schedule, "Uniform Building By-Laws" MDC Publishers Printers Sdn. Bhd.

2. Cato, W. W., \& Mobley, R. K. (2002). Computer-managed maintenance systems a step-by-step guide to effective management of maintenance, labor, and inventory (2nd ed.). Boston: Butterworth-Heinemann.

3. Wireman, T. (2004). Maintenance Training. Benchmarking best practices in maintenance management (p. 85). New York: Industrial Press.

4. Bagadia, K. (2006). Overview of CMMS. Computerized maintenance management systems made easy how to evaluate, select, and manage CMMS (pp. 5-31). New York: McGraw-Hill. 